\title{
Metabolic response of early-lactating cows exposed to transport and high altitude grazing conditions
}

\author{
M. Kreuzer ${ }^{1}$, W. Langhans ${ }^{1}$, F. Sutter ${ }^{1}$, R. E. Christen ${ }^{1}$, H. Leuenberger ${ }^{1}$ and P. L. Kunz ${ }^{2}$ \\ ${ }^{1}$ Institute of Animal Sciences, ETH Zurich, ETH Centre/LFW, CH-8092 Zurich, Switzerland \\ ${ }^{2}$ Swiss College of Agriculture, $\mathrm{CH}-3052$ Zollikofen, Switzerland
}

\section{Abstract}

The metabolic response of dairy cows to high as opposed to low altitude conditions ( $2000 \mathrm{~m}$ v. $400 \mathrm{~m}$ above sea level) was determined. In the first experiment, four cows were subjected to a series of measurements before, during and after transport from lowland to high altitude pasture. During transport, cortisol, L-lactate and non-esterified fatty acids were significantly elevated but decreased within 1 to 3 days to initial levels. After transport, $\beta$-hydroxybutyrate and the thyroid hormones immediately increased and returned within 3 weeks to initial levels. Plasma urea increased during transport and subsequently was at an intermediate level due to the different diet. There were no direct carry-over effects of transport on metabolic traits during pasturing.

In the second experiment, three groups of six different dairy cows were either grazed in one of two consecutive years or kept inside (2nd year only). Lowland sojourn lasted for 4 weeks, and high altitude period for 8 weeks. At the end of high altitude sojourn, both outside and inside groups were found still to have significantly higher plasma cortisol values than at lowland. Thyroid hormones and ketosis related metabolites sharply increased at the start of the alpine period and were elevated for 1 to 3 weeks thereafter. According to the hormonal and metabolic profiles, the permanently housed cows did not benefit from the less adverse climatic conditions and the lower physical strain. Plasma urea closely reflected dietary changes in the ratio of nitrogen to fermentable organic matter. Plasma protein, albumin, creatinine, and liver enzyme activities were not affected by transport or high altitude sojourn in both experiments. The results indicate that the metabolic response to transport and high altitude conditions can be mostly explained by the efforts to cover the additional energy requirements. Overall the data suggest a wide but nevertheless limited ability of early-lactating cows to adapt to high altitude conditions.

Keywords: adaptation, dairy cows, high altitude, metabolites, transport.

\section{Introduction}

High altitude pasturing is common during summertime in mountainous regions worldwide. In lactating cows, this system causes additional energy demands during and after transportation to high altitude by various factors such as metabolic disturbances associated with transport, physiological consequences of lower oxygen pressure at high altitude as well as increased demands to cope with harsh climatic and unfavourable topographic conditions (e.g. Bianca and Näf, 1979; Aceves et al., 1987). An immediate metabolic response of dairy cows is necessary during and shortly after transport to high altitude. This excludes effective slow adaptative processes which may, however, be expressed with increasing duration of high altitude grazing. The few results on the effects of high altitude pasture on food consumption and milk yield (cf. Zemp et al., 1989b; Christen et al., 1996) suggest a limited adaptability of lactating cows to high altitude conditions. Zemp et al. (1989a) found indications of an increased risk of metabolic disorders of cows at high altitude compared with lowland pastured cows, although blood samples were not obtained before 2 weeks after transport. The aim of the present study was to follow the evolution of metabolite and hormone profiles in early-lactating cows by frequent measurements before, during and after transport from lowland to high altitude sojourn. This allowed the monitoring of adaptation responses and of any carry-over effects of transport occurring in the period of high altitude sojourn. Furthermore, by simultaneously recording data of cows kept inside and outside at high altitude, the importance of 
climatic and physical strain additional to the low oxygen pressure could be separately assessed.

\section{Material and methods}

In two experiments, both the short-term and the long-term metabolic response of dairy cows to high as opposed to low altitude pasturing $(2000 \mathrm{~m} \mathrm{v}$. $400 \mathrm{~m}$ above sea level) and transport was followed. In compliance with common summer feeding practice, grass was supplemented with $4 \mathrm{~kg}$ dry matter (DM) per head of whole-crop maize (artificially dried) at lowland. At high altitude only pasture grass was provided. The cows were offered a salt-mineral mixture $(1: 1 ; \mathrm{Ca}: \mathrm{P}, 3: 1)$ on pasture (licking blocks) and inside (mixture spread on grass).

\section{Experiment 1}

Experiment 1 lasted from 2 weeks before until 4 weeks after transport from lowland to high altitude pasture, with the data collection focussing on the time around transport (short-term response). Four lactating cows (two Simmental and two Holstein cows) weighing 621 (s.d. 69) $\mathrm{kg}$ were used. On average, they had calved 5 weeks before transport and their average milk yield in the 4 weeks before transport was 25.6 (s.d. 2.6) kg day. Blood samples were obtained from the jugular vein after $1 \mathrm{~h}$ of food deprivation (lowland, at $15.00 \mathrm{~h}$; high altitude, at $17.30 \mathrm{~h}$ ). Samples were taken on days $13,10,6,3$, and 1 before transport and 1 to $4,6,8,10,12,13,16,20$, 23 , and 27 days after transport. On the day of transport, the cows remained on the vehicle for $6 \mathrm{~h}$ (from 06.15 to $12.15 \mathrm{~h}$ ) with the real transport time lasting only for $4.5 \mathrm{~h}(07.15$ to $11.45 \mathrm{~h})$. On this day using permanent catheters 14 blood samples were taken: three of them before the cows entered the transport vehicle (at 05.00, 05.30, and $06.00 \mathrm{~h}$ ), seven samples during the time the cows remained on the vehicle (at 07.00, 07.45, 08.45, 09.45, 10.45, 11.30, and $12.00 \mathrm{~h}$ ), and four samples after the cows had left the vehicle and were tethered in the cowshed (at 12.30, $14.00,15.00$ and $16.00 \mathrm{~h}$ ) before they were let out on pasture. In the figures, these sampling dates are given in relation to the time when the cows entered the vehicle. The vehicle was stationary at the times blood samples were taken during transport. On the vehicle, the four cows were separated by wooden barriers. Space allowance per cow was $0.9 \mathrm{~m} \times 2.2 \mathrm{~m}$, and the cows were tied at right angles to the travelling direction. For total and separate collection of faeces and urine during transport, the cows were equipped with urinals attached to velcrose straps which were sealed to the skin around the vulva. The animals had been adapted to the urinals for $8 \mathrm{~h}$ daily during the last 3 days before transport. The hind legs of the cows were placed into open $0.9 \mathrm{~m} \times 1 \mathrm{~m}$ plastic containers of $0.2 \mathrm{~m}$ height for faeces collection. The cows were not given food from $18.00 \mathrm{~h}$ on the day before transport until they entered the alpine cowshed at noon on the day of transport. They were weighed immediately before and after transport. Cows were grazed for the rest of the experiment and milk yield as well as live weight were recorded daily.

\section{Experiment 2}

Experiment 2 lasted from 4 weeks before until 8 weeks after transport to high alpine pasture, focussing on the long-term response to high altitude grazing. The 8 weeks at high altitude accounted for about two-thirds of the whole pasturing season at this location. Twenty-four multiparous cows (eight Simmental, eight Brown Swiss and eight Holstein cows), which had calved 2 to 4 weeks prior to the start of the experiment, were allocated to four groups of six cows (inside/outside; years $\mathrm{A}$ and $\mathrm{B}$ ) in a balanced way as far as breed, milk yield and live weight were concerned. The average milk yield during the 2 weeks prior to transport to high altitude pasture was 28.7 (s.d. 4.1$) \mathrm{kg} /$ day and live weight was 605 (s.d. 64) $\mathrm{kg}$. In year $\mathrm{A}$, all 12 cows were grazing on lowland. At high altitude, six cows were at pasture and the other six were tethered in a common cowshed. This inside group of cows expressed an extreme suppression of food intake and milk yield at high altitude. Starting with similar average values at lowland, DM intake in this group was $9 \cdot 2$ (s.d. $3 \cdot 3$ ) $\mathrm{kg} /$ day and milk yield was $16 \cdot 2$ (s.e. $3 \cdot 0) \mathrm{kg} /$ day in the 1st week of high altitude sojourn whereas the values of the corresponding grazed group were 19.3 (s.d. 3.8 ) kg dry matter intake per day and 23.5 (s.d. 4.7) kg milk per day. Possibly this was an adverse reaction to tethering inside. One of the cows developed clinical ketosis. This group was not further considered for statistical evaluation. In year B, the two groups of six lactating cows were either at pasture or kept inside at both locations. This design allowed consideration of differences between years and separation of the particular effect of high altitude from additional climatic and topographic effects. In every experimental week, at least two blood samples were collected at $14.30 \mathrm{~h}$ (inside) and at $15.15 \mathrm{~h}$ (outside) after $1 \mathrm{~h}$ of fasting with the animals at pasture tethered to trees. Seven samples were obtained in the 1st week of high altitude sojourn, a further seven samples in weeks 2 and 3 and four samples in week 8 . No measurements were made during transport. At each blood collecting date, live weight and rectal temperature were recorded. Further details on this experiment, particularly the double indicator technique to estimate food intake and the results on production parameters, are described elsewhere (Christen et al., 1996). 


\section{Analyses}

Blood samples were immediately cooled on ice. All blood and plasma traits for both experiments were analysed according to standard procedures (Blum et al., 1985). Most metabolites and hormones were determined in plasma obtained from heparinized samples. For glucose and non-esterified fatty acids (NEFA) analyses, fluoride oxalate was used to obtain plasma. Blood was deproteinized with $1: 1 \mathrm{v} / \mathrm{v}$ of $0.7 \mathrm{~mol} / 1$ perchloric acid for the determination of L-lactate and $\beta$-hydroxybutyrate (BHB). The concentrations of L-lactate, glucose, NEFA, BHB, urea, creatinine, protein and albumin as well as the plasma activities of aspartate aminotransferase and -glutamyl transpeptidase were photometrically analysed using standard enzymatic methods (Boehringer, Mannheim, and Gilford Diagnostics, USA) adapted to the COBAS MIRA autoanalyser (Roche, Basle, Switzerland). Commercially available radioimmuno assays were used to measure plasma cortisol, 3, 5, 3'-triiodothyronine $\left(\mathrm{T}_{3}\right)$ and thyroxin $\left(\mathrm{T}_{4}\right)$ (Diagnostics Product Corporation, USA), as well as immunoreactive insulin (Pharmacia, Sweden). In experiment 2, non-protein bound $\mathrm{T}_{3}$ and $\mathrm{T}_{4}$ concentrations in plasma were also determined by radioimmuno assays (Amersham, England).

\section{Statistical evaluation}

All data were evaluated by SAS (version 6.04, SAS Inc., Cary, NC). In both experiments, repeated measurement models were applied for analysis of variance. Breed was not regarded as a factor since all cows had a similar performance and equal numbers of each breed were used. In experiment 1 , three periods of time were defined for analysis of variance: the time before transport (five samples), the time of transport (seven samples) and the first 3 days after transport (three samples). The Tukey procedure was performed as a post-hoc test of significance $(P<0.05)$ between periods of time. Furthermore, significance of variation of the parameters during the actual transport period was evaluated by the Friedman non-parametric repeated measures test.

In experiment 2 all individual data obtained in the last 2 weeks at lowland (P1), in week 1 (P2), in weeks 2 with 3 (P3) and in week 8 (P4) were used as separate periods of time to calculate average values per animal. Group, period of time and group $\times$ period interactions were considered in the model designed for analysis of variance. One member of the inside group in year $B$ had to be excluded from statistical evaluation due to extremely unusual and deviating values.

\section{Results}

Experiment 1

During the $6 \mathrm{~h}$ of transport (including vehicle standing time), the initial average of live weight of $621 \mathrm{~kg}$ declined by 23.0 (s.d. 6.4) kg. This weight loss comprised proportionately 0.448 of faeces and 0.217 of urine. Accordingly, the evaporative weight loss was calculated to be $7 \cdot 7$ (s.d. 2.3) kg. The additional live-weight loss during high altitude sojourn was comparably low (about $5 \mathrm{~kg} /$ week, on average). Milk yield declined proportionately by 0.18 during the 4 weeks of alpine sojourn.

Plasma cortisol (average peak concentration of $180 \mathrm{nmol} / \mathrm{l}$; basal level of about 8 to $10 \mathrm{nmol} / 1$ ) was significantly elevated during transport (Table 1 ), and decreased to initial level a few hours after the end of transport (Figure 1). Plasma $T_{3}$ and $T_{4}$ were not affected by transport but were significantly higher for several days at high altitude grazing when compared to the values measured during transport (Table 1, Figures 2 and 3). On average over days 1 to 3 of the alpine sojourn, $\mathrm{T}_{3}$ and $\mathrm{T}_{4}$ were

Table 1 Experiment 1: short-term response of cows in blood plasma concentrations of metabolites and hormones to $4.5 \mathrm{~h}$ vehicle transport and to high altitude pasturet

\begin{tabular}{|c|c|c|c|c|c|c|}
\hline \multirow[t]{2}{*}{ Period of time } & \multicolumn{2}{|c|}{ Before transport } & \multicolumn{2}{|c|}{ During transport } & \multicolumn{2}{|c|}{1 to 3 days after transport } \\
\hline & Mean & s.e. & Mean & s.e. & Mean & s.e. \\
\hline Cortisol (nmol/1) & $10 \cdot 2^{b}$ & $2 \cdot 02$ & $147 \cdot 0^{\mathrm{a}}$ & $21 \cdot 00$ & $7 \cdot 6^{b}$ & 0.48 \\
\hline $\mathrm{T}_{3}(\mathrm{nmol} / \mathrm{l})$ & $1.68^{a b}$ & $0-162$ & $1 \cdot 51^{b}$ & $0 \cdot 117$ & $2 \cdot 19 a$ & $0 \cdot 147$ \\
\hline $\mathrm{T}_{4}(\mathrm{nmol} / \mathrm{l})$ & $60 \cdot 7^{a b}$ & $2 \cdot 70$ & $58 \cdot 2^{b}$ & $5 \cdot 17$ & $90 \cdot 8^{a}$ & $9 \cdot 74$ \\
\hline Insulin (pmol/l) & $43 \cdot 9$ & $7 \cdot 06$ & $29 \cdot 9$ & $2 \cdot 95$ & $41 \cdot 7$ & $7 \cdot 57$ \\
\hline Glucose $(\mathrm{mmol} / \mathrm{l})$ & 3.29 & 0.062 & $3 \cdot 45$ & $0 \cdot 129$ & $3 \cdot 05$ & 0.066 \\
\hline L-lactate $(\mathrm{mmol} / \mathrm{l})$ & $0.47 \mathrm{~b}$ & 0.021 & $0.76^{\mathrm{a}}$ & 0.067 & $0.54^{b}$ & 0.029 \\
\hline NEFA (mmol/l) & $0 \cdot 45^{b}$ & $0 \cdot 031$ & $2 \cdot 10^{\mathrm{a}}$ & 0.061 & $0.56^{b}$ & 0.069 \\
\hline $\mathrm{BHB}(\mathrm{mmol} / \mathrm{l})$ & $0 \cdot 58^{\mathrm{b}}$ & $0 \cdot 051$ & $0.62^{b}$ & $0 \cdot 048$ & $1 \cdot 17^{a}$ & 0.063 \\
\hline Urea (mmol/l) & $3 \cdot 18^{\mathrm{b}}$ & 0.558 & $4 \cdot 80^{\mathrm{a}}$ & 0.428 & $4 \cdot 31^{\mathrm{ab}}$ & 0.391 \\
\hline
\end{tabular}

a,b Means on the same line carrying no common superscript are significantly different $(P<0-05)$.

+ Abbreviations: $\mathrm{T}_{3}=$ triiodothyronine; $\mathrm{T}_{4}=$ thyroxin; NEFA $=$ non-esterified fatty acids; $\mathrm{BHB}=\beta$-hydroxybutyrate. 

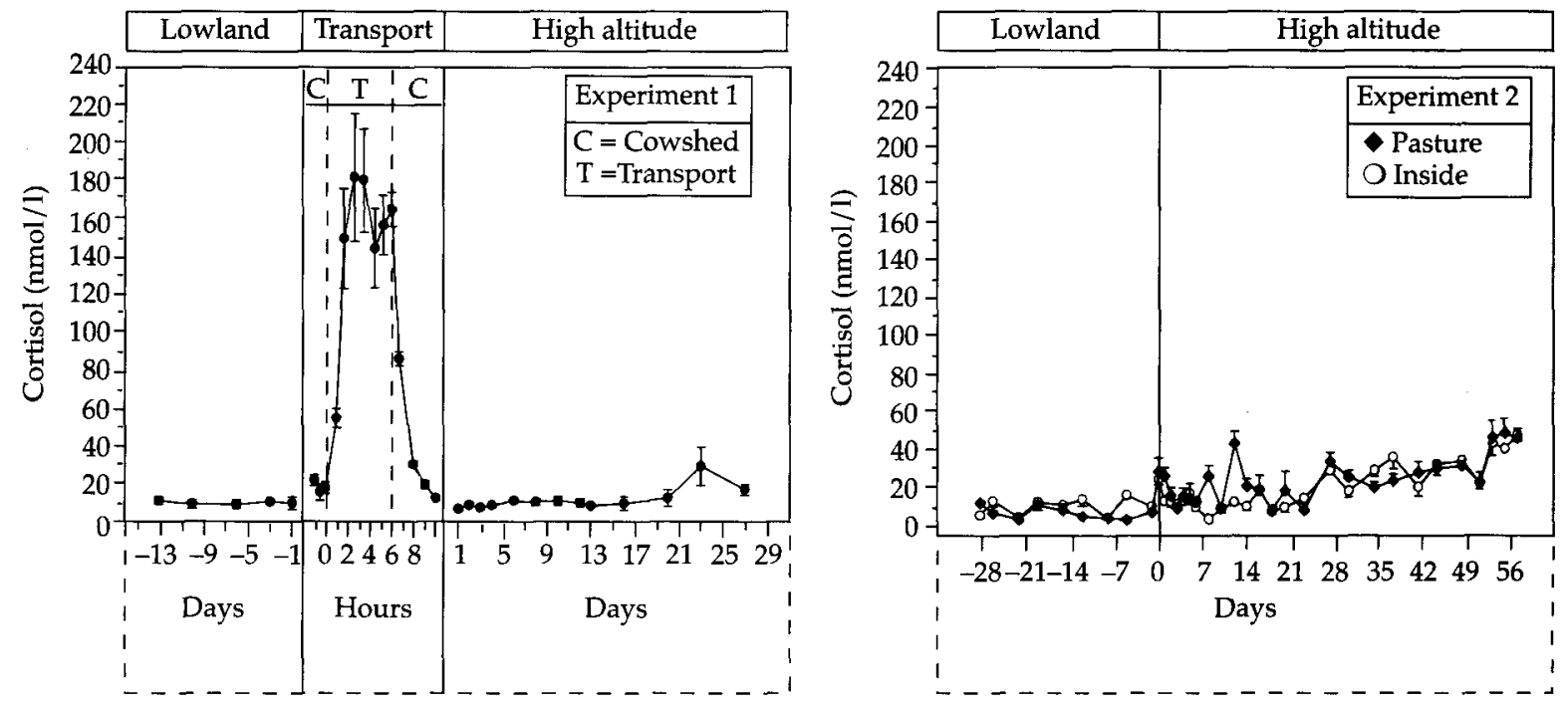

Figure 1 Response of plasma cortisol to transport and high altitude sojourn (means and s.e.).

proportionately 0.30 and 0.50 above the respective lowland levels. After 2 weeks of high altitude pasture initial levels were again reached.

Between periods of time a certain non-significant variation of plasma immunoreactive insulin and glucose occurred (Table 1; Figures 4 and 5). Within the actual transport period, plasma glucose significantly increased $(P<0.01$; Friedman test). Blood L-lactate and plasma NEFA levels were significantly elevated during transport (Table 1) and almost immediately returned to about the lowland levels after transport (Figures 6 and 7). In contrast plasma BHB did not respond to transport (Table 1) but significantly increased from the 2 nd day of alpine grazing onwards, with a quite slow decline lasting the 4 weeks of experiment (Figure 8). Plasma urea was significantly higher in the transport period (Table 1) with an increase occurring during transport (Figure 9; $P<0.01$; Friedman test) and remained at
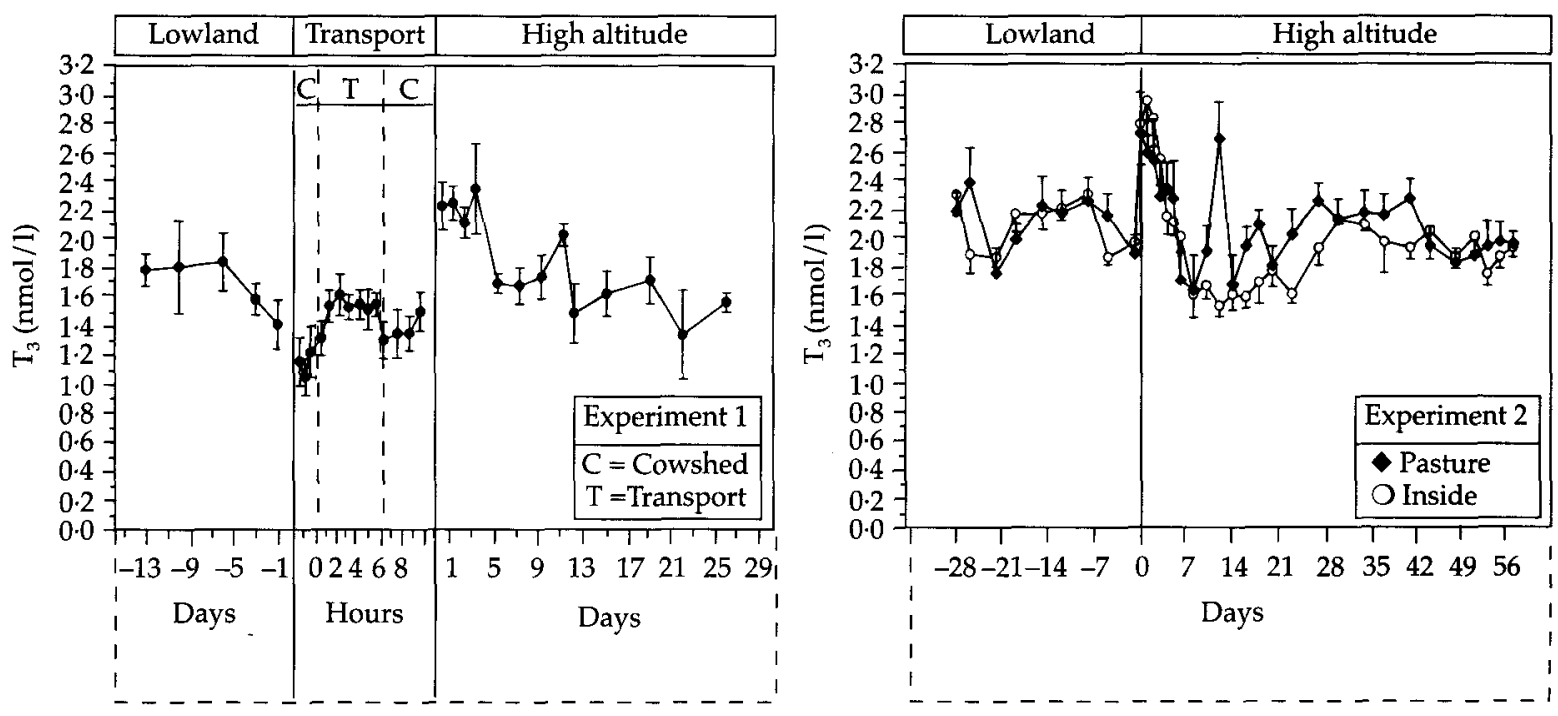

Figure 2 Response of plasma triiodothyronine $\left(\mathrm{T}_{3}\right)$ to transport and high altitude sojourn (means and s.e.). 

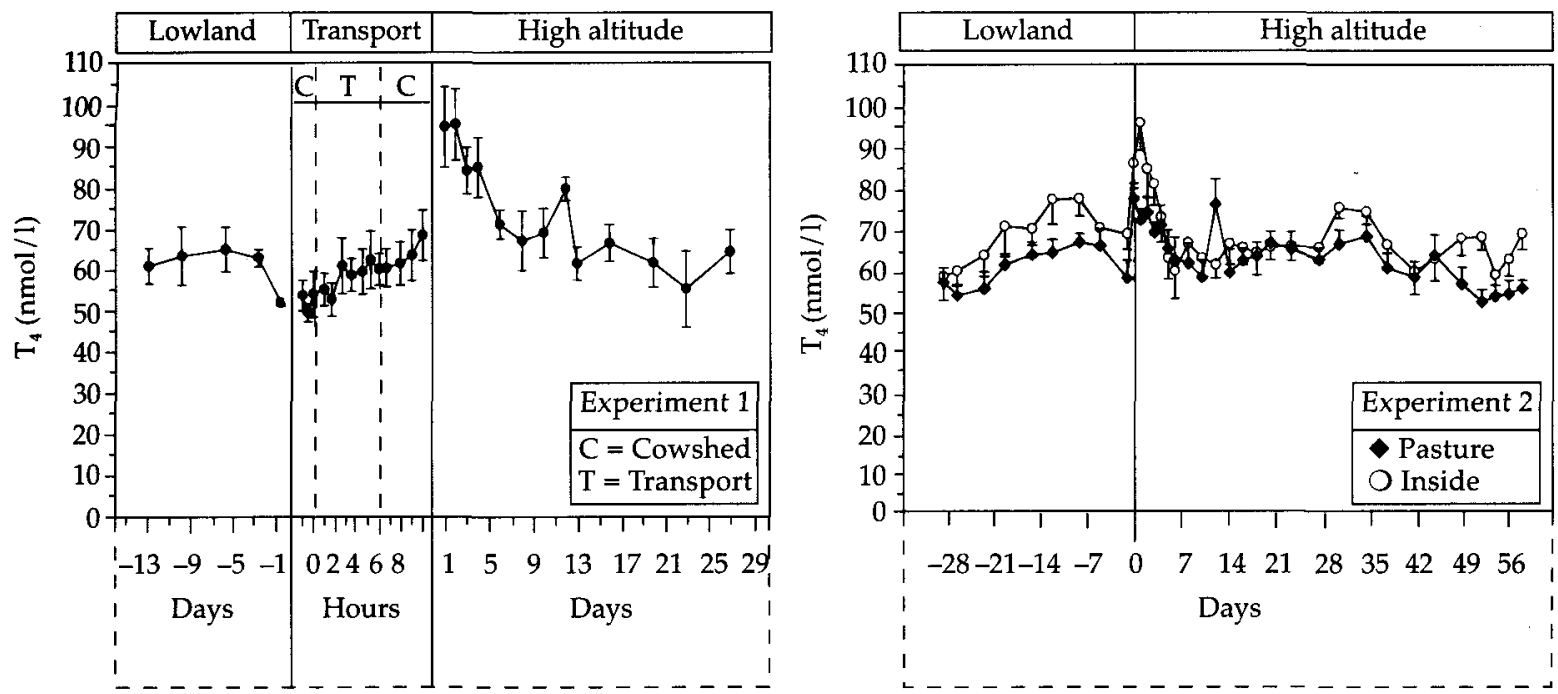

Figure 3 Response of plasma thyroxin $\left(\mathrm{T}_{4}\right)$ to transport and high altitude sojourn (means and s.e.).

an intermediate level for several weeks of alpine grazing.

\section{Experiment 2}

There were only minor differences in weight loss and milk yield decline during the alpine period between the grazed cows of both years and the cows inside in year B. On average, live weights of the cows decreased from $605 \mathrm{~kg}$ at lowland by 42 (s.d. 16) kg $(0.069)$ in the 1st week of alpine sojourn, and were still lower than lowland values by 0.048 at the end of the alpine period. Milk yield declined

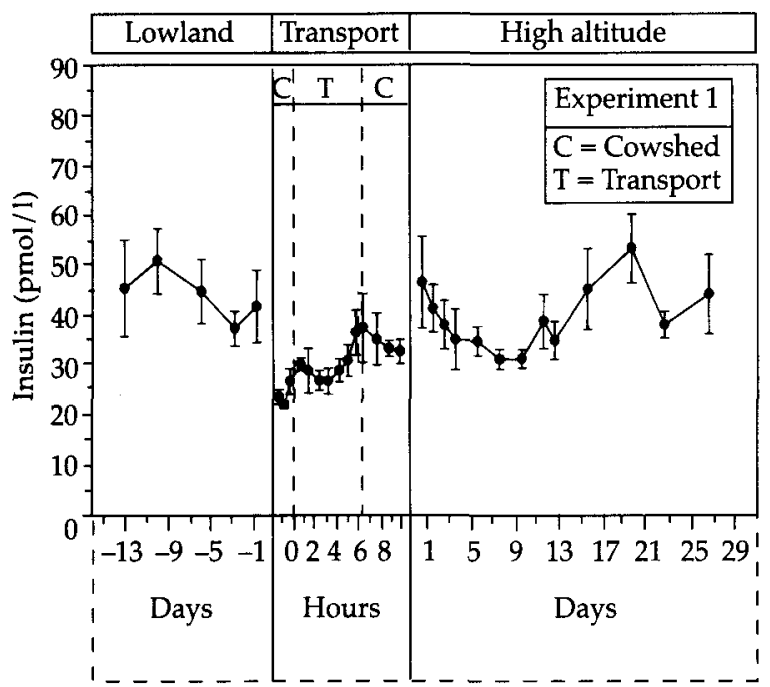

proportionately by 0.50 during the 8 weeks of alpine sojourn compared with the average of the last 2 weeks of lowland sojourn. In neither of the three experimental groups did rectal temperature noticeably change during the experiment. On average, 38.8 (s.d. 0.2 ) ${ }^{\circ} \mathrm{C}, 38.6$ (s.d. 0.2 ) ${ }^{\circ} \mathrm{C}$ and 38.5 (s.d. $0 \cdot 1)^{\circ} \mathrm{C}$ were found on pasture in years $\mathrm{A}$ and $\mathrm{B}$ and inside, respectively.

In Table 2 results on blood traits are given for periods P1 and P4, i.e. lowland and 8th week of high altitude sojourn. Parameters in the grazing cows of

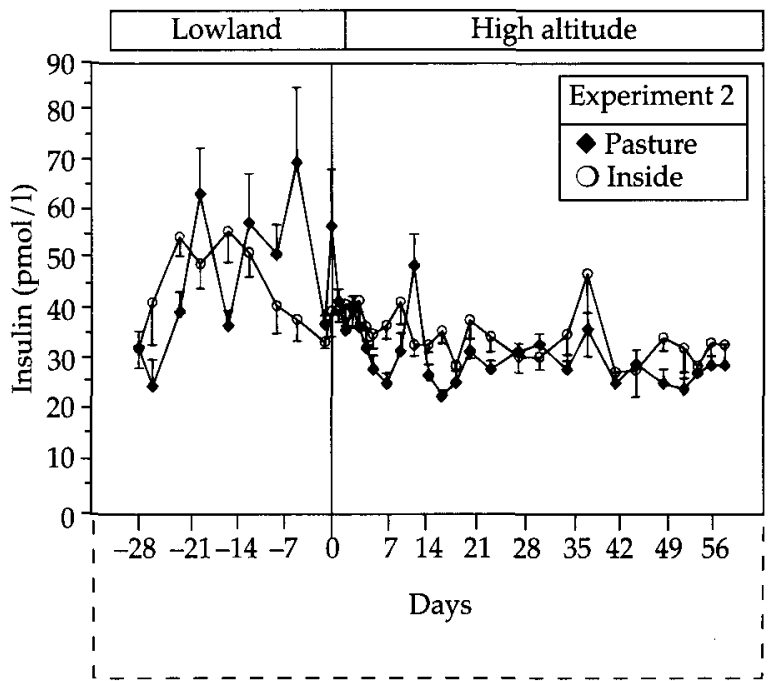

Figure 4 Responses of plasma immunoreactive insulin to transport and high altitude sojourn (means and s.e.). 
Table 2 Experiment 2: long-term response of cows in blood plasma concentrations of metabolites and hormones to high altitude conditions (lowland v. 8th week at high altitude)

\begin{tabular}{|c|c|c|c|c|c|c|c|c|c|c|c|c|c|c|c|c|c|c|}
\hline \multirow{4}{*}{$\begin{array}{l}\text { Group } \\
\text { Period of timet } \\
\text { Location }\end{array}$} & \multicolumn{5}{|c|}{ Year A / Pasture } & \multicolumn{5}{|c|}{ Year B / Pasture } & \multicolumn{5}{|c|}{ Year B / Inside } & \multirow{2}{*}{\multicolumn{3}{|c|}{$\begin{array}{c}\text { Treatmen } \\
\text { effects }\end{array}$}} \\
\hline & \multicolumn{3}{|c|}{ P1 } & \multicolumn{2}{|c|}{$\mathbf{P} 4$} & \multicolumn{3}{|c|}{ P1 } & \multicolumn{2}{|c|}{ P4 } & \multicolumn{2}{|l|}{$\mathrm{P} 1$} & \multicolumn{3}{|c|}{ P4 } & & & \\
\hline & \multicolumn{3}{|c|}{ Lowland } & \multicolumn{2}{|c|}{$\begin{array}{c}\text { Alpine } \\
\text { (8th week) }\end{array}$} & \multicolumn{2}{|c|}{ Lowland } & & \multicolumn{2}{|c|}{$\begin{array}{c}\text { Alpine } \\
\text { (8th week) }\end{array}$} & \multicolumn{2}{|c|}{ Lowland } & \multicolumn{3}{|c|}{$\begin{array}{c}\text { Alpine } \\
\text { (8th week) }\end{array}$} & \multirow{2}{*}{ 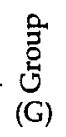 } & \multirow{2}{*}{$\begin{array}{c}\stackrel{D}{Z} \\
\stackrel{D}{D} \\
(P)\end{array}$} & \multirow{2}{*}{$\underset{0}{\times}$} \\
\hline & Mean & s.e. & & Mean & s.e. & Mean & s.e. & & Mean & s.e. & Mean & s.e. & & Mean & s.e. & & & \\
\hline Cortisol (nmol/1) & $10 \cdot 3$ & $1 \cdot 57$ & $* *$ & $18 \cdot 2$ & 1.64 & $4 \cdot 6$ & 1.90 & $* * *$ & $39 \cdot 8$ & $4 \cdot 53$ & $10 \cdot 1$ & $2 \cdot 08$ & $* * *$ & $37 \cdot 1$ & $2 \cdot 65$ & & $* * *$ & $* * *$ \\
\hline $\mathrm{T}_{3}(\mathrm{nmol} / \mathrm{l})$ & $2 \cdot 52$ & 0.216 & & $2 \cdot 16$ & 0.056 & $2 \cdot 13$ & $0 \cdot 171$ & & 1.93 & $0 \cdot 122$ & $2 \cdot 10$ & 0.038 & & 1.88 & 0.086 & & $* * *$ & \\
\hline $\mathrm{T}_{4}(\mathrm{nmol} / \mathrm{l}$ & $61 \cdot 1$ & $7 \cdot 17$ & & 51.5 & $3 \cdot 44$ & $64 \cdot 0$ & $3 \cdot 17$ & & 53.9 & $2 \cdot 51$ & $73 \cdot 0$ & $4 \cdot 51$ & $*$ & $64 \cdot 8$ & $4 \cdot 30$ & & $* * *$ & \\
\hline Insulin (pmol/l) & $38 \cdot 1$ & $3 \cdot 12$ & & $34 \cdot 8$ & $1 \cdot 76$ & $50 \cdot 2$ & 6.90 & $*$ & $27 \cdot 3$ & 1.96 & $43 \cdot 8$ & 3.46 & & $31 \cdot 9$ & $3 \cdot 87$ & & $* * *$ & ** \\
\hline Glucose $(\mathrm{mmol} / \mathrm{l})$ & 3.57 & 0.080 & $* *$ & $3 \cdot 25$ & 0.092 & $3 \cdot 38$ & $0 \cdot 207$ & & $3 \cdot 61$ & 0.080 & $3 \cdot 46$ & 0.076 & & $3 \cdot 39$ & 0.068 & & $* * *$ & $* *$ \\
\hline L-lactate (mmol/1) & 0.50 & 0.053 & $*$ & 0.67 & 0.041 & $0 \cdot 66$ & $0 \cdot 031$ & & 0.65 & 0.020 & 0.64 & 0.016 & & 0.67 & 0.057 & & $* *$ & $* * *$ \\
\hline NEFA (mmol/l) & 0.40 & 0.030 & $* *$ & 0.25 & 0.016 & $0 \cdot 28$ & $0 \cdot 045$ & & $0 \cdot 22$ & $0 \cdot 034$ & 0.31 & 0.045 & * & $0 \cdot 12$ & 0.012 & & $* * *$ & \\
\hline $\mathrm{BHB}(\mathrm{mmol} / \mathrm{l})$ & $0 \cdot 50$ & 0.036 & * & 0.54 & 0.041 & $0 \cdot 87$ & 0.258 & & 0.43 & $0 \cdot 035$ & 0.56 & 0.057 & & 0.59 & 0.030 & & $* * *$ & $* *$ \\
\hline Urea $(\mathrm{mmol} / 1)$ & $1 \cdot 66$ & 0.081 & $* * *$ & $4 \cdot 61$ & 0.231 & $2 \cdot 66$ & $0 \cdot 194$ & $* * *$ & 3.91 & 0.179 & $2 \cdot 37$ & $0 \cdot 159$ & $* * *$ & 3.69 & 0.091 & $1 *$ & $* * *$ & $* * *$ \\
\hline
\end{tabular}

+ Significantly different means of periods P1 and P4 within the same group are separated by asterisks.

$\ddagger$ Significance of group, period of time and group $\times$ period interaction $(G \times P)$ from the analysis of variance considering all groups and periods of time (P1, P2, P3 and P4).

year A behaved relatively similar to those in year B. Therefore, the figures present the continuous evolution of the parameters from year B only.

On pasture and inside, plasma cortisol constantly increased with increasing time of high alpine sojourn (Figure 1) and was significantly higher than the initial lowland levels in every experimental group after 8 weeks of high altitude sojourn (Table 2). Howevar, the increase was small compared with the effects of transport (Figure 1). Similar to experiment 1 , plasma $T_{3}$ and $T_{4}$ sharply increased after transport and returned to initial levels within about 1 to 2 weeks (Figures 2 and 3). Equal or slightly lower levels than at lowland occurred at the end, irrespective of location or year (Table 2). Nonprotein bound $\mathrm{T}_{3}$ and $\mathrm{T}_{4}$ accounted proportionately for 0.013 (s.d. 0.0014 ) and 0.0011 (s.d. 0.0002) of total $T_{3}$ and $T_{4}$ respectively, with only a small variation within and between groups and periods of time.
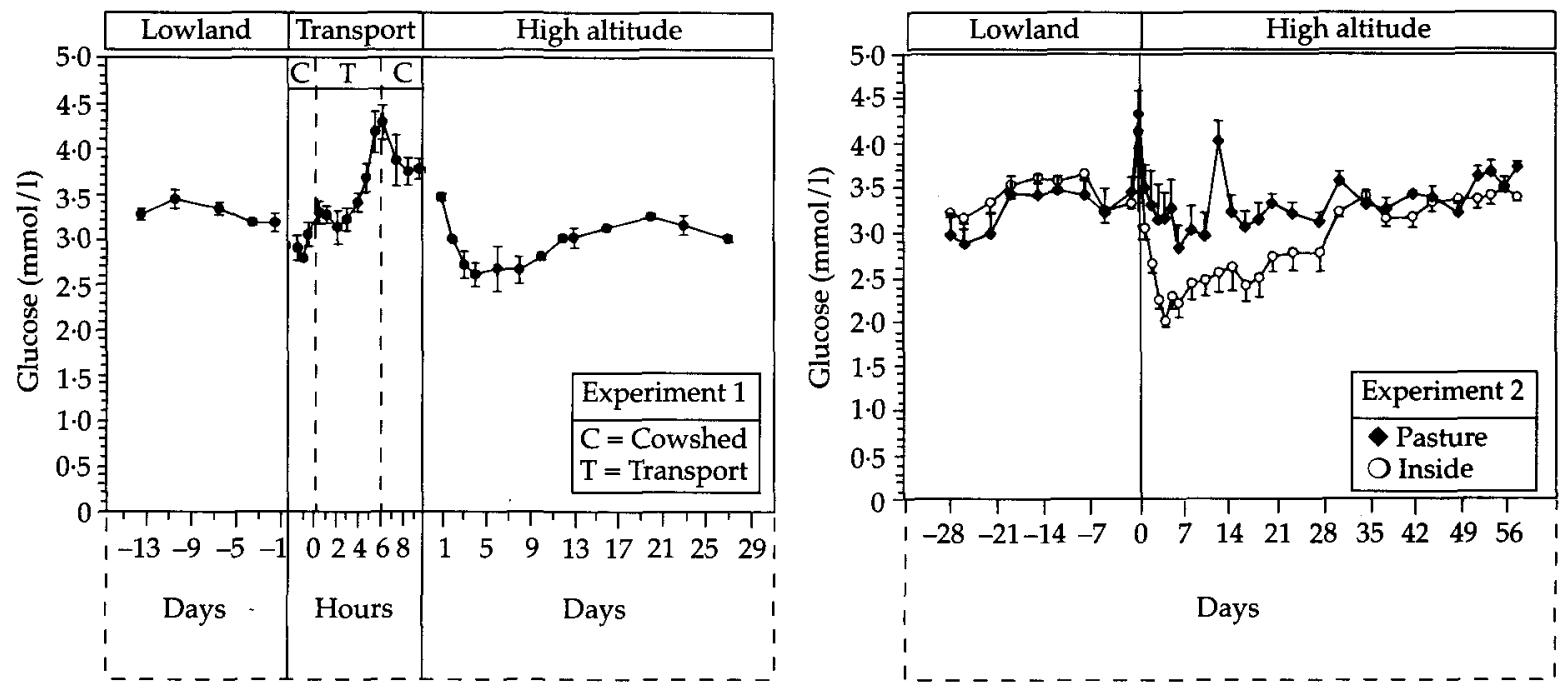

Figure 5 Response of plasma glucose to transport and high altitude sojourn (means and s.e.) 



Figure 6 Response of blood L-lactate to transport and high altitude sojourn (means and s.e.).

Insulin, glucose and lactate were only slightly different from the lowland values shortly after the start of alpine grazing in the grazed cows (Figures 4, 5 and 6). In contrast, the inside group showed a sharp initial decline in plasma glucose at the start of high altitude sojourn (different at $P<0.05$ from the values of the simultaneously pastured cows in weeks 2 with 3 of high altitude sojourn) without a corresponding reaction in insulin or lactate. The long-term effects of high altitude grazing on insulin, glucose and lactate were not totally consistent between years, although some significant differences from lowland occurred (Table 2).



Blood BHB and plasma NEFA were considerably elevated for about 2 weeks after transport (Figures 7 and 8). After 8 weeks of alpine sojourn mostly similar or even lower levels than at lowland were found (Table 2). The initial increases in NEFA were lower and in BHB were higher inside than in the pastured cows (Figure 8; statistically significant in weeks 2 with 3 of high altitude sojourn). On high altitude pasture, plasma urea was constantly high irrespective of group (Figure 9, Table 2) with concentrations of about twice the lowland levels (2.23 (s.d. 0.56), 4.00 (s.d. 1.19), 3.76 (s.d. 0.59) and 4.07 (s.d. 0.58 ) $\mathrm{mmol}$ urea/1 plasma, on average, in

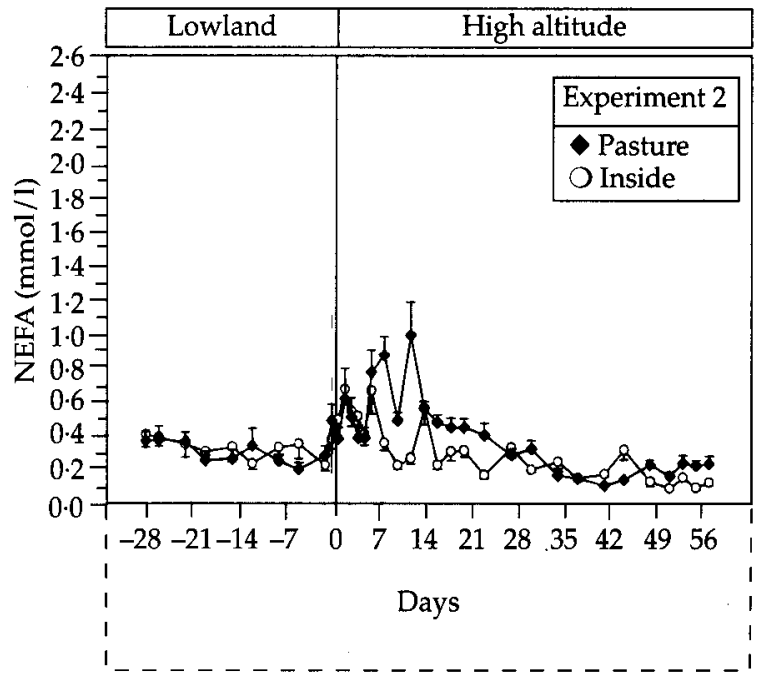

Figure 7 Response of plasma non-esterfied fatty acids (NEFA) to transport and high altitude sojourn (means and s.e.). 

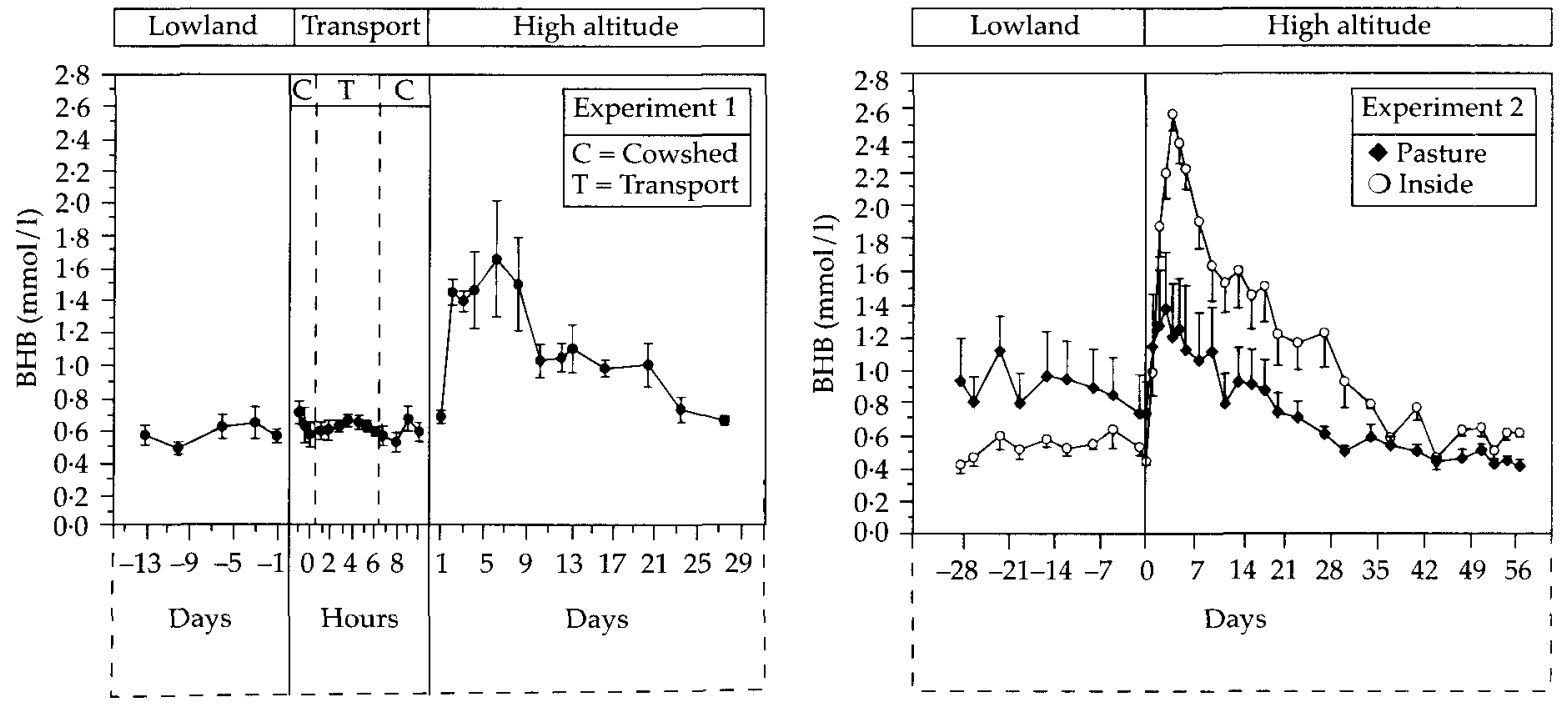

Figure 8 Response of blood $\beta$-hydroxybutyrate (BHB) to transport and high altitude sojourn (means and s.e.).

the periods P1, P2, P3 and P4, respectively). Each of the parameters listed in Table 2 showed highly significant time-dependent variations, and for several parameters group $X$ period interactions were observed.

Other blood plasma traits

In both experiments, neither transport nor high altitude sojourn significantly affected the parameters reflecting metabolic protein turn-over (total protein, albumin, creatinine) as well as the plasma activities of certain liver enzymes. The results for these parameters are not presented in the tables or figures. In experiments 1 and 2 respectively, on average 83.2 (s.d. 5.3) and 82.2 (s.d. 4.7 ) g total protein, 46.7 (s.d. 1.9 ) and 43.4 (s.d. 2.4 ) g albumin, as well as 94.6 (s.d. 20.7) and 80.1 (s.d. 11.5) $\mu \mathrm{g}$ creatinine per litre of plasma were measured. The respective average units of plasma enzyme activity per litre were 41.8 (s.d. 7.5) and 36.8 (s.d. 5.6) for aspartate aminotransferase,
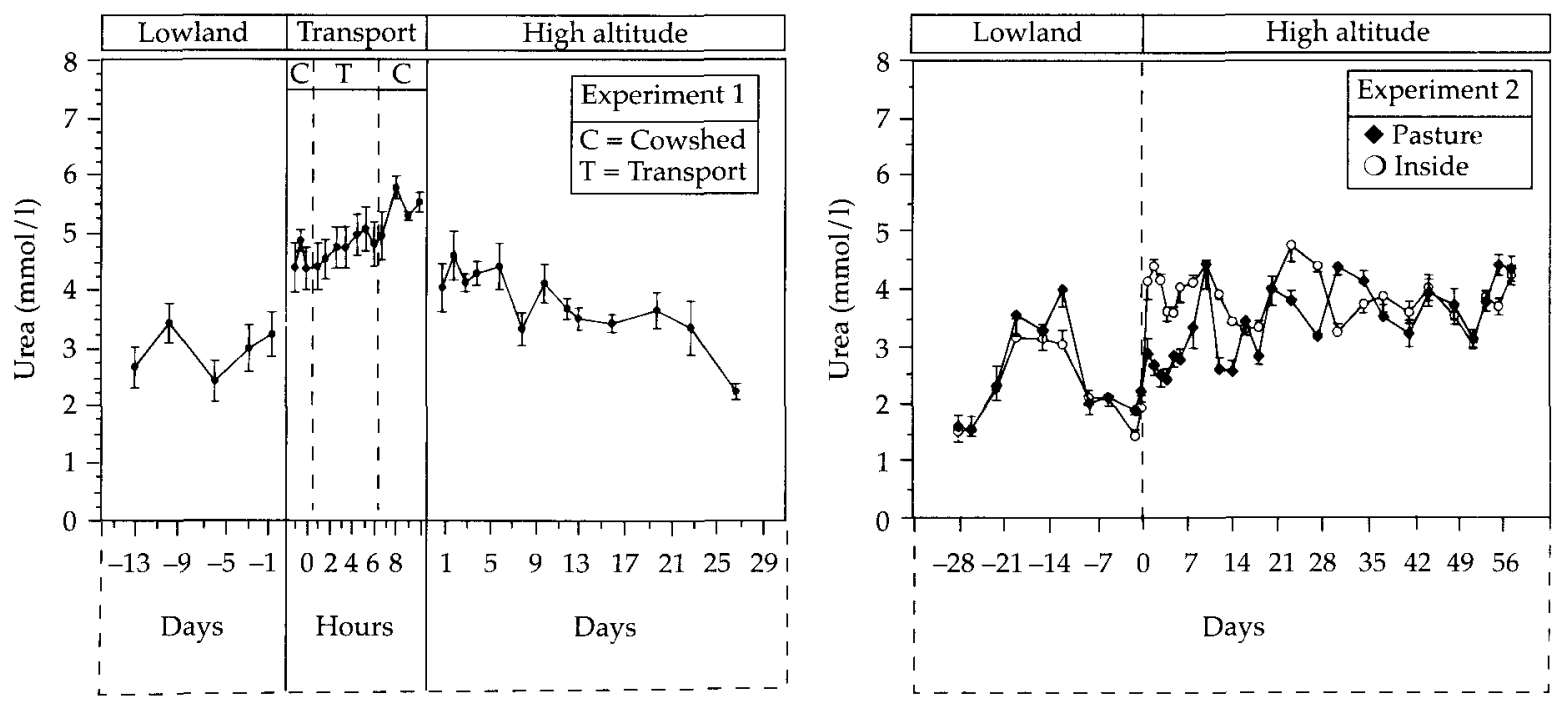

Figure 9 Response of plasma urea to transport and high altitude sojourn (means and s.e.). 
and 11.5 (s.d. 4.6 ) and 11.7 (s.d. $2 \cdot 7$ ) for $\gamma$-glutamyl transpeptidase.

\section{Discussion}

Effects of transport

The clear transport-induced increase in cortisol, glucose, lactate and NEFA levels is characteristic of an immediate stress response. The increase in plasma cortisol by transport stress was reported to have its maximum after $3 \mathrm{~h}$ of transport in sheep (Cockram et. al., 1996). Motion, noise, vibration (Cockram et al., 1996) and space allowance (Tarrant et al., 1992) have been discussed as the most important stressors during transport. The onset of adaptive mechanisms could explain why plasma cortisol levels declined in the study of Cockram et al. (1996) after several hours of transport. However, the $4.5 \mathrm{~h}$ of transport in experiment 1 of the present study would not appear sufficiently long to allow such a noticeable decrease in plasma cortisol.

The additional energy required for stress compensation and balance keeping during travel (Schrama et al., 1996) was obviously covered by mobilization of fat (increased NEFA level) and glycogen (increasing glucose level), however without a corresponding increase in plasma insulin level. The transport effects on plasma glucose reported from other studies are highly controversial (reviewed by Horton et al., 1996), maybe due to differences in road construction and mode of driving. The response in lactate and NEFA resembled the kind and speed of alteration found in cows subjected to draught work (Zerbini et al., 1995).

The significant and almost continuous increase in plasma urea during transport might have resulted from an increased metabolic protein degradation as a consequence of a temporary inhibition of milk formation or from a lower rate of urea recycling due to fasting. The period without food supply accounted for more than $12 \mathrm{~h}$ at the start of transport in experiment 1. Plasma protein, albumin and creatinine were not affected by transport indicating that mobilization of body protein should have played a minor rôle. Growing animals may show increased levels of plasma albumin and/or total protein when transported for long periods of time (Cole et al., 1986; Tarrant et al., 1992; Cockram et al., 1996). However this increase could also result from dehydration (Cockram et al., 1996). Non-evaporative water loss was found by Cole et al. (1986) to be higher in transported than in fasted steers, and faeces and urine excretion during transport accounted for about 0.03 of live weight, similar to the present results $(0.03$ to 0.04 of live weight). A considerable part of the immediate weight loss from lowland to high altitude in experiment 1 could be explained by excreta. Overall, despite the additional requirements for milk synthesis, the general metabolic response of cows to transport seems to be quite similar to that of growing animals on which most transport studies are focussed.

\section{Effects of high altitude pasturing}

In contrast to transport stress, high altitude conditions caused an almost completely different pattern of metabolic response. This and the transient nature of the transport effects suggest that direct carry-over effects of transport stress were low. Besides the different response of plasma NEFA, quite similar initial effects of high-altitude grazing occurred in both experiments. The values obtained at lowland had also been similar. Insulin, glucose and lactate were not different from lowland levels after the end of transport. Accordingly, adaptation in the glucose-related parameters (plasma glucose, insulin and blood lactate) were rapid. In contrast, there was a long-term reduction in plasma glucose and insulin in cows and steers exposed to high altitude pasture in the studies of Bossart et al. (1985) as well as Zemp et al. (1989a).

Elevated levels of the thyroid hormones $\mathrm{T}_{3}$ and $\mathrm{T}_{4}$ are considered as indicators of a higher metabolic energy turn-over with the consequence of a higher heat production. This explains reduced thyroid hormone levels during energy deficiency (Kunz et al., 1985; Ronge et al., 1988) but also increased levels at low ambient temperatures, as was found in the case of $T_{3}$ by Aceves et al. (1987). Considering that ambient temperature was considerably lower at high altitude than at lowland (Christen et al., 1996), the effect of cold exposure on heat production (Sano et al., 1995) obviously exceeded the decrease in heat production expected in the state of deficient energy supply (Ortigues and Vermorel, 1996). According to the present data, it required about 1 week until other adaptive mechanisms replaced the $T_{3}$ and $T_{4}$ effects to sustain body temperature at low ambient temperatures. Zemp et al. (1989a) also noted no effects on thyroid hormone levels of high altitude sojourn when blood samples were obtained after 2 weeks of an alpine environment. After 12 weeks of high altitude pasture, thyroid hormone concentrations in steers were even lower than in a corresponding lowland control group (Bossart et al., 1985). However, growing animals may have an increased energy demand with increasing time of fattening, whereas lactating cows widely compensated the initial lack of energy by an equivalent decline in milk yield.

A longer adaptation time was required for the parameters reflecting a long-term lack of metabolic 
energy like NEFA and BHB. Concentrations of both metabolites were elevated directly from the start of alpine sojourn, although already at lowland plasma NEFA levels had indicated a catabolic situation as is characteristic for early-lactating cows (Kunz et al., 1985). The initial increase lasted for 2 (NEFA; only experiment 2) to 3 weeks (BHB). Similar effects have been observed by Zemp et al. (1989a), comparing cows grazing at high altitude with a control group remaining on lowland pasture. The particular conditions of high altitude grazing increase energy requirements considerably. The pastured cows in experiment 2 were estimated to require twice as much energy to cover maintenance requirements than is necessary under lowland conditions (Christen et al., 1996). Cold stress may contribute to the increased energy demand, further increasing plasma NEFA levels (Sano et al., 1995). Cows are able to produce milk partly from body reserves. Accordingly, in both experiments a persistent though not dramatic loss of live weight occurred which might partly be attributed to the use of body stores additional to a certain dehydration at high altitude, possible differences in water intake and a reduced gastrointestinal and udder fill. This mobilization of body reserves, however, takes place at a cost of body condition loss which resulted in the initial alterations of the metabolic traits measured. Quite good adaptation within a few weeks seems to be achieved by a rapid decline in milk yield (Zemp et al., 1989b; Christen et al., 1996) and also by a higher oxygen uptake capacity of the blood due to the continuously increasing hematocrit (Bianca and Näf, 1979; Zemp et al., 1989a). An undesired consequence of the milk yield depression by a period of deficient energy is its partially irreversible nature (Kirchgessner et al., 1986) which leads to persistently low yields even on subsequent lowland pasture (Zemp et al., 1989b). This emphasizes that grazing alone is not sufficient to cover the additional requirements at high altitude.

As an astonishing long-lasting effect, a significant and sustained elevation in plasma cortisol was observed during high altitude pasturing in experiment 2, although at a considerably lower level than was caused by transport. Since this occurred on pasture and inside, it could reflect a chronic stress situation induced by low oxygen pressure and insufficient energy supply. In contrast, part of the day-to-day variations in cortisol could be attributed to individual stress situations like changing pastures or immediate cold exposure as for instance on day 12 with only the pastured cows responding by an increase in plasma cortisol (Figure 1). The evidence given by the present data was, however, limited since only few blood samples were obtained per week during the high altitude period and only one time of day was available.
The small variation found in the plasma activities of liver enzymes with values generally far below clinical relevance demonstrates that stress caused by high altitude sojourn was not intense enough to cause liver damage. In contrast, Baumgartner (1978) noted a certain increase in the activity of the same liver enyzmes in cows pastured at $1600 \mathrm{~m}$.

The results for plasma protein, albumin and creatinine indicate that no excessive expenditure of body protein took place. Plasma albumin was also not affected by high altitude pasturing in steers (Bossart et al., 1985), and Zemp et al. (1989a) found gradually decreasing albumin levels in high altitude pastured but not in lowland grazing dairy cows. Plasma urea clearly reflected the alterations occurring in the ratio of nitrogen to fermentable organic matter as was demonstrated earlier (Kreuzer et al., 1991) with lower plasma urea concentrations at lowland when whole-crop maize supplements were offered. The level of dietary crude protein obviously was without major effect on the other plasma parameters as could be expected from earlier findings (Kreuzer et al., 1991).

\section{Responses in different years}

Overall, despite quite differing climatic and dietary conditions (Christen et al., 1996), the differences found between the responses of the grazing cows in the two subsequent years were small as far as plasma levels and responses of metabolites and hormones to high altitude conditions are concerned. The level and significance of the long-term response slightly differed in some traits (Table 2). It seems reasonable to assume that favourable climatic conditions and, independent from that, high food quality, alleviates metabolic adaptation.

\section{Inside $\mathrm{v}$. outside high altitude effects}

Energy requirements were expected to be lower inside than outside since the inside group did not suffer from the adverse climatic and topographic conditions in addition to the low oxygen pressure. Even though the air temperature in the cowshed at high altitude $\left(17.6^{\circ} \mathrm{C}\right)$ was lower on average than at lowland $\left(21.2^{\circ} \mathrm{C}\right)$, the lack of wind and the smaller day to night variations in ambient temperature should have provided less cold stress than outside. Nevertheless thwarting exercise in a relatively cold environment may have been responsible for the increase in plasma $T_{3}$ and $T_{4}$ in the inside group during the 1st week.

Cows kept inside at high altitude showed an even greater adverse response in parameters related to metabolic energy supply than the grazing cows. Plasma glucose was clearly reduced for about 4 weeks (without corresponding alteration in insulin) 
and blood BHB was elevated to about twice the level of the pastured cows. However, the higher concentration of BHB found in plasma of the inside group does not necessarily reflect a higher energy deficit than in the grazing cows, since plasma NEFA levels were not different at the same time and motion is known to help to eliminate ketone bodies (Buddeke, 1989). It seems that grazing helps the cows to adapt to the particular high altitude conditions, however at cost of a considerably higher energy expenditure, which is compensated by a correspondingly higher food intake (Christen et al., 1996).

\section{Conclusions}

The results of both experiments indicate that cows respond intensively to transport and high altitude conditions. Metabolic adaptation to the immediate energy deficit on high altitude pasture seems to require at least 3 weeks, which is a considerable part of the whole high alpine season. Other data suggest that with preceding high altitude sojourn the level of additional maintenance requirements decreases (Christen et al., 1996). The week-to-week variations and the significant group $\times$ period of time interactions indicate gradual and group-dependent kinetics of metabolic adaptation. The final adaptation resulted from direct metabolic consequences and a depression in milk yield.

\section{Acknowledgements}

We thank Dr Ruth Messikommer for assisting with the experimental techniques, the staff of the ETH experimental station Weissenstein for their assistance in carrying out the experiment and Nigel Berry for his help with preparing the manuscript.

\section{References}

Aceves, C., Romero, C., Sahagun, L. and Valverde-R, C. 1987. Thyroid hormone profile in dairy cattle acclimated to cold or hot environmental temperatures. Acta Endocrinologica 114: 201-207.

Baumgartner, W. 1978. Untersuchungen über den Einfluss der Alpung auf verschiedene Blut parameter und Pansensaftkriterien beim Rind. Wiener Tierärztliche Monatsschrift 65: 172-175.

Bianca, W. and Näf, F. 1979. Responses of cattle to the combined exposure, to diurnal temperature rhythm ( -5 to $25^{\circ} \mathrm{C}$ ) and to simulated high-altitude $(4000 \mathrm{~m})$. International Journal of Biometeorology 23: 299-310.

Blum, J. W., Jans, F., Moses, W., Fröhli, D., Zemp, M., Wanner, M., Hart, I. C., Thun, R. and Keller, U. 1985. Twentyfour-hour pattern of blood hormone and metabolite concentrations in high-yielding dairy cows: effects of feeding low or high amounts of starch, or crystalline fat. Zentralblatt Veterinär-Medizin, A 32: 401-418.
Bossart, M. A., Leuenberger, H., Kuenzi, N. and Blum, J. W. 1985. Levels of hormones and metabolites, insulin responses to glucose infusions, glucose tolerances and growth rates in different breeds of steers: studies during and after an alpine sojourn. Zeitschrift für Tierzüchtung und Züchtungsbiologie 102: 23-33.

Buddeke, E. 1989. Grundrisse der Biochemie, 8th edition. De Gruyter, Berlin.

Christen, R. E., Kunz, P. L., Langhans, W., Leuenberger, H., Sutter, F. and Kreuzer, M. 1996. Productivity, requirements and efficiency of feed and nitrogen utilization of grass-fed early lactating cows exposed to high alpine conditions. Journal of Animal Physiology and Animal Nutrition 76: 22-35

Cockram, M. S., Kent, J. E., Goddard, P. J., Waran, N. K., McGilp, I. M., Jackson, R. E., Muwanga, G. M. and Prytherch, S. 1996. Effect of space allowance during transport on the behavioural and physiological responses of lambs during and after transport. Animal Science 62: 461-477.

Cole, N. A., Phillips, W. A. and Hutcheson, D. P. 1986. The effect of pre-fast diet and transport on nitrogen metabolism of calves. Journal of Animal Science 62: 1719-1731.

Horton, G. M. J., Baldwin, J. A., Emanuele, S. M., Wohlt, J. E. and McDowell, L. R. 1996. Performance and blood chemistry in lambs following fasting and transport. Animal Science 62: 49-56.

Kirchgessner, M., Kreuzer, M. and Roth-Maier, D. A. 1986. Milk urea and protein content to diagnose energy and protein malnutrition of dairy cows. Archives of Animal Nutrition 36: 192-197.

Kreuzer, M., Kirchgessner, M. and Blum, J. W. 1991. Konzentration von Hormonen und Stoffwechselparametern im Blutplasma von Kühen während und nach unterschiedlicher Rohproteinzufuhr. Journal of Animal Physiology and Animal Nutrition 65: 11-20.

Kunz, P. L., Blum, J. W., Hart, I. C., Bickel, H. and Landis, J. 1985. Effects of different energy intakes before and after calving on food intake, performance and blood hormones and metabolites in dairy cows. Animal Production 40: 219-231.

Ortigues, I. and Vermorel, M. 1996. Adaptation of whole animal energy metabolism to undernutrition in ewes: influence of time and posture. Animal Science 63: 413-422.

Ronge, H., Blum, J., Clement, C., Jans, F., Leuenberger, $H$. and Binder, H. 1988. Somatomedin $\mathrm{C}$ in dairy cows related to energy and protein supply and to milk production. Animal Production 47: 165-183.

Sano, H., Nakamura, S., Kobayashi, S., Takahashi, H. and Terashima, Y. 1995. Effect of cold exposure on profiles of metabolic and endocrine responses and on responses to feeding and arginine injection in sheep. Journal of Animal Science 73: 2054-2062.

Schrama, J. W., Heetkamp, M. J. W., Verstegen, M. W. A., Schouten, W. G. P., Veen, F. van der and Helmond, F. A. 1996. Responses of young calves, on two levels of feeding, to transportation. Animal Science 63: 79-89.

Tarrant, P. V., Kenny, F. J., Harrington, D. and Murphy, M. 1992. Long distance transportation of steers to slaughter: 
effect of stocking density on physiology, behaviour and carcass quality. Livestock Production Science 30: 223-238.

Zemp, M., Blum, J. W., Leuenberger, H. and Künzi, N. $1989 \mathrm{a}$. Influence of high altitude grazing on productive and physiological traits of dairy cows. II. Influence on hormones, metabolites and haematological parameters. Journal of Animal Breeding and Genetics 106: 289-299.

Zemp, M., Leuenberger, H., Künzi, N. and Blum, J. W. $1989 \mathrm{~b}$. Influence of high altitude grazing on productive and physiological traits of dairy cows. I. Influence on milk production and body weight. Journal of Animal Breeding and Genetics 106: 278-288.
Zerbini, E., Gemeda, T., Wold, A. G., Nokoe, S. and Demissie, D. 1995. Effect of draught work on performance and metabolism of crossbred cows. 2. Effect of work on roughage intake, digestion, digesta kinetics and plasma metabolites. Animal Science 60: 369-378.

(Received 8 December 1997-Accepted 7 May 1998) 